\title{
Penggunaan Bahasa Indonesia yang Baik dan Benar serta Etika Menghubungi Dosen melalui Aplikasi WhatsApp
}

\author{
Chairunnisa1, Nur Hasanah $^{2}$, Ahmad Ari Masyhuri' ${ }^{3}$, Daffa Febriansyah ${ }^{4}$, Denok Sunarsi ${ }^{5}$ \\ 1,2STKIP Kusumanegara Jakarta, Indonesia \\ 3,5Universitas Pamulang, Tangerang Selatan, Banten, Indonesia \\ ${ }^{4}$ Universitas Veteran Jakarta, Indonesia \\ Email: chairunnisa.khis@stkipkusumanegara.ac.id¹, nur.hasanah@stkipkusumanegara.ac.id, \\ arymasyhuri@gmail.com, daffafebriansyah85@gmail.com, denoksunarsi@mail.unpas.ac.id
}

\begin{tabular}{l}
\hline Article Info \\
\hline Article History \\
Received: 2021-11 \\
Revised: 2021-12-1 \\
Published: 2022- \\
\\
Keywords: \\
Indonesian; \\
Ethics; \\
Communication; \\
WhatsApp.
\end{tabular}

Article Info

(1)

Revised: 2021-12-15

Published: 2022-01-03

Indonesian

Ethics;

WhatsApp.

\begin{abstract}
The use of good and correct Indonesian and the ethics of students in contacting lecturers have shifted since they were spoiled by the ease of communication. If we discuss the world of students in the era before Android, of course the communication process between students and lecturers is generally done directly without media. Changes that occur among students in communicating and interacting with lecturers are caused by various things at this time. The purpose of this study was to take an inventory and describe the use of good and correct Indonesian when contacting lecturers. This study uses quantitative research methods, namely using the google form platform to survey data in the form of numbers for this research. The results of the study indicate that there are still many students who do not understand and understand the use of good and correct Indonesian and ethics in communicating with what has been proven from the results of the previous survey, which are new students who in fact have not adapted to the world of lectures. Of course we need to prevent this as a form of our attention to communication ethics.
\end{abstract}

\begin{tabular}{l}
\hline Artikel Info \\
\hline Sejarah Artikel \\
Diterima: 2021-11-20 \\
Direvisi: 2021-12-15 \\
Dipublikasi: $2022-01-03$
\end{tabular}

Kata kunci:

Bahasa Indonesia; Etika;

Komunikasi;

WhatsApp.

\begin{abstract}
Abstrak
Penggunaan Bahasa Indonesia yang baik dan benar serta etika mahasiswa dalam mengubungi dosen semakin bergeser sejak dimanjakan oleh kemudahan komunikasi. Apabila kita menalar sejenak mengenai dunia mahasiswa pada era sebelum adanya android, tentu proses komunikasi antara mahasiswa dengan dosen umumnya dilakukan secara langsung tanpa media. Perubahan-perubahan yang terjadi pada kalangan mahasiswa dalam berkomunikasi dan berinteraksi dengan dosen disebabkan oleh berbagai hal pada zaman seperti ini. Tujuan penelitian ini adalah untuk menginventarisasi dan mendeskripsikan karakteristik pemakaian Bahasa Indonesia yang baik dan benar ketika menghubungi dosen. Penelitian ini menggunakan metode penelitian kuantitatif yaitu menggunakan platform google form untuk melakukan survei data dalam bentuk angka terhadap penelitian ini. Hasil penelitian menunjukkan bahwa masih banyak mahasiswa yang belum paham dan mengerti mengenai pemakaian Bahasa Indonesia yang baik dan benar serta etika dalam berkomunikasi kepada dosen yang telah dibuktikan dari hasil kuesioner terlebih adalah mahasiswa baru yang notabennya belum menyesuaikan diri pada dunia perkuliahan. Hal ini tentu perlu kita cegah sebagai bentuk perhatian kita terhadap etika berkomunikasi.
\end{abstract}

\section{PENDAHULUAN}

Etika berkomunikasi sangat diperlukan oleh semua orang terhadap lawan komunikasi. Termasuk mahasiswa yang harus tepat dalam berkomunikasi secara profesional karena setelah lulus mahasiswa akan masuk ke dunia kerja yang menuntut profesionalisme yang tinggi. Hal ini mengajarkan bagaimana berkomunikasi dengan baik, sopan dan santun. Komunikasi merupakan sistem aliran yang menghubungkan dan membangkitkan kinerja apa yang kita tuju. Selain itu komunikasi adalah alat untuk melangsungkan interaksi dan bertukar pesan baik dengan dosen, orang tua, ataupun teman sejawat. Sehingga dapat dikatakan bahwa komunikasi merupakan suatu kekuatan di dalam kehidupan karena memungkinkan suatu struktur dan tujuan bisa terwujud, Komunikasi yang etis yaitu ketika seseorang berkomunikasi secara jujur dan kooperatif. Pemakaian bahasa Indonesia yang baik dan benar serta etika dalam komunikasi pun di pengaruhi oleh prinsip moral sesuai dengan lingkungan sosialnya. Seperti yang dikemukakan oleh (Suherman, 2019) bahwa dalam hidup bermasyarakat, seseorang akan terisolasi apabila tidak pernah berkomunikasi dengan orang lain. Akibat keterisolasian ini dikhawatirkan dapat menimbulkan permasalahan yang kompleks. 
Hakikatnya komunikasi adalah proses pernyataan isi pikiran atau perasaan seseorang pada orang lain dengan mengunakan bahasa Indonesia yang baik dan benar. Komunikasi berarti menyampaikan pesan oleh komunikator kepada komunikan.

Penelitian ini dilakukan untuk meningkatkan kembali etika agar menjadi manusia yang memiliki moral,sopan, dan santun salah satunya dengan berkomunikasi dengan tujuan etika sebagai hal dasar bagi mahasiswa. Jadi mempelajari komunikasi dengan etika adalah mewujudkan nilai moral mahasiswa yang baik, menjadikan etika sebagai modal utama moralitas pada kehidupan dimanapun dan dengan keadaan apapun, karena etika yang baik, mencerminkan prilaku yang baik sedangkan etika yang buruk mencerminkan prilaku yang buruk pula. Salah satu aplikasi pesan teks yang sekarang ramai digunakan yaitu aplikasi whatsapp. Kehadiran aplikasi whatsapp tentunya memberikan kemudahan bagi sebagian orang namun ada pula yang justru menyalahgunakannya.

Di zaman seperti ini, menuntut manusia bergerak secara cepat untuk semua urusan, sehingga beberapa alat dibuat dan bertambah untuk memudahkan dalam berkomunikasi. Whatsaap salah satu platform perpesanan secara instan terbesar dengan pengunaan terbanyak, memiliki fitur yang lengkap dan mumpuni. Akan tetapi beberapa pengguna aplikasi ini kurang memperhatian aspek sopan santun berkomunikasi sehingga menimbulkan rasa risih, kurang sopan, kurang nyaman, dan lain sebagainya.

\section{METODE PENELITIAN}

Disituasi pandemi seperti ini, mengharuskan kita semua untuk berada dirumah. Hal ini karena tetap di rumah saja merupakan salah satu cara memutus mata rantai penyebaran covid -19 . Oleh karena itu sebagai penulis, hal ini menjadi salah satu hambatan dalam pembuatan artikel ini. Terkait judul yang penulis ambil mengenai "Penggunaan Bahasa Indonesia yang Baik dan Benar serta Etika Menghubungi Dosen melalui Aplikasi WhatsApp", maka lokasi dan waktu penelitian yang penulis lakukan adalah penyebaran angket di ruang lingkup mahasiswa UPN Veteran Jakarta tahun 2021 dengan jangka waktu 3 hari yaitu pada tanggal 5-7 November 2021, Pada penelitian ini, penulis memilih untuk menggunakan metode penelitian kuantitatif. Menurut Kasiran (2018), yang mengartikan bahwa penelitian kuantitatif adalah upaya seorang peneliti menemukan pengetahuan menyugu- hkan data dalam bentuk angka. Angka-angka yang diperoleh inilah yang digunakan untuk melakukan analisa keterangan. Dalam bahasa lebih sederhana lagi, penelitian kuantitatif adalah penelitian ilmiah yang disusun secara tersistematis terhadap bagian-bagian dan mencoba untuk menemukan kausalitas untuk mengetahui keterkaitan. Sedangkan, Beryman mendefinisikan penelitian kuantitatif adalah penelitian yang melibatkan teori, desain, hipotesis dan menentukan subjek. Kemudian didukung dengan pengumpulan data, pemprosesan data dan menganalisa data sebelum dilakukan penulisan kesimpulan.

Teknik analisis data yang kami gunakan adalah teknik statistik deskriptif. Menurut (Pangestu Subagyo, 2003) yang dimaksud sebagai statistika deskriptif adalah bagian statistika mengenai pengumpulan data, penyajian, penentuan nilai-nilai statistika, pembuatan diagram atau gambar mengenai sesuatu hal, disini data yang disajikan dalam bentuk yang lebih mudah dipahami atau dibaca.

\section{HASIL DAN PEMBAHASAN}

A. Hasil Penelitian

Setelah dilakukan penelitian dan analisis kuesioner yang telah dibagikan dan diisi oleh responden yang telah ditetapkan yaitu mahasiwa program studi hukum, maka peneliti menyimpulkan bahwa:

1. Grafik Mahasiswa UPN Veteran Jakarta yang pernah menghubungi dosen.

Dalam diagram ini, menunjukan bahwa sebagian mahasiswa pernah menghubungi dosen dengan keperluan yang berbedabeda. Hal ini dibuktikan oleh hasil kuesioner yang menunjukkan angka $71 \%$ responden menjawab pernah menghubungi dosen dan 29\% responden menjawab tidak pernah menghubungi dosen.

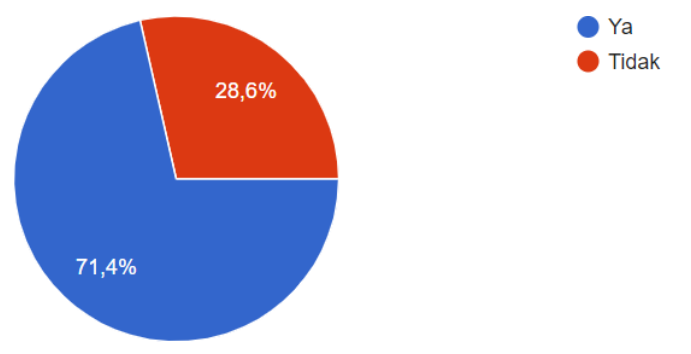

Gambar 1. Grafik Intensitas mahasiswa yang menghubungi Dosen

Sumber: Dokumen Pribadi, 2021 
2. Grafik fasilitas pesan yang digunakan mahasiswa dalam menghubungi dosen.

Dalam diagram ini, menunjukkan bahwa mahasiswa yang pernah menghubungi dosen menggunakan aplikasi komunikasi yang beragam. Hal ini dibuktikan oleh hasil kuesioner yang menunjukkan 50\% responden menggunakan pesan singkat, 14\% responden menggunakan aplikasi WhatsApp, 7\% menggunakan telepon, dan sisanya tidak pernah menghubungi dosen.
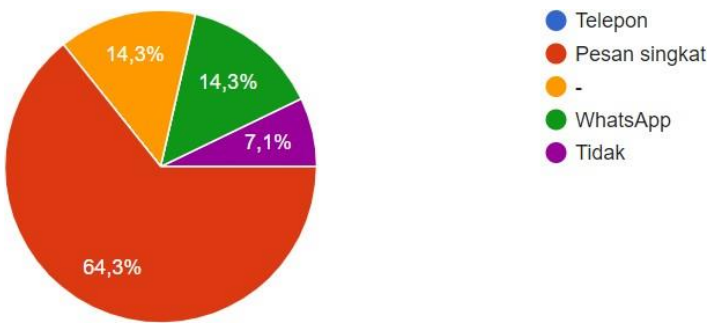

Gambar 2. Grafik Fasilitas yang digunakan Mahasiswa dalam menghubungi Dosen

Sumber: Dokumen Pribadi, 2021

3. Grafik mahasiswa yang pernah tidak direspons oleh dosen

Dalam diagram ini, menunjukkan bahwa sebagian mahasiswa tidak pernah direspon oleh dosen. Hal ini dibuktikan oleh 57\% responden menjawab pernah direspons dan 43\% responden menjawab pernah tidak direspons oleh dosen.

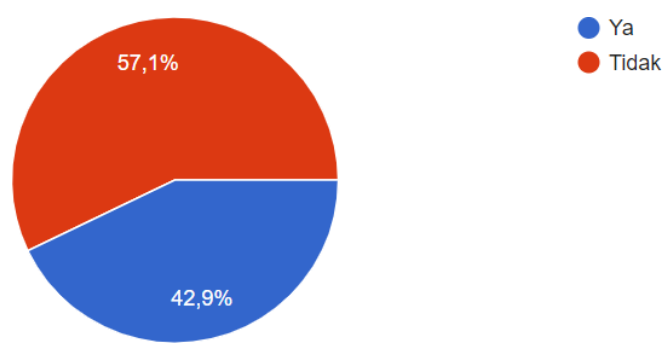

Gambar 3. Grafik Mahasiswa yang pernah tidak direspon oleh Dosen Sumber: Dokumen Pribadi, 2021

4. Grafik mahasiswa sudah menggunakan Bahasa Indonesia yang baik dan benar serta etika komunikasi.

Dalam diagram ini menunjukan bahwa sebagian besar responden sudah menggunakan bahasa Indonesia yang biak dan benar, dibuktikan dengan hasil penelitain bahwa $92,9 \%$ responden sudah melakukannya.

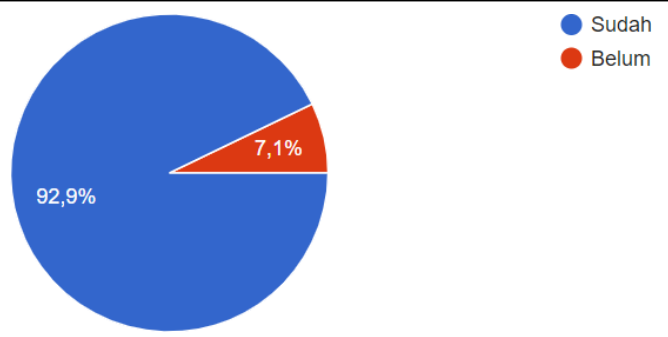

Gambar 3. Grafik mahasiswa sudah menggunakan Bahasa Indonesia yang baik dan benar serta etika komunikasi Sumber: Dokumen Pribadi, 2021

B. Pembahasan

1. Karakteristik bahasa indonesia yang baik dan benar

Dengan gambaran kondisi tersebut, dimana pengetahuan masyarakat masih kurang tepat dan terbatas berkaitan dengan penggunaan bahasa indonesia yang baik dan benar dalam kehidupan seharihari. Maka, diperlukan pemahaman dan pengetahuan lebih terkait penggunaan bahasa indonesia yang baik dan benar. Berbahasa indonesia yang baik adalah berbahasa indonesia yang sesuai dengan tempat tempat terjadinya konteks berbahasa, sesuai dengan siapa lawan bicara, dan sesuai dengan topik pembicaraannya. Bahasa indonesia yang baik tidak selalu harus baku, yang perlu diperhatikan dalam berbahasa indonesia yang baik adalah pemanfaatan ragam yang tepat dan serasi menurut golongan, penutur dan jenis pemakaian bahasa itulah. Karena pada dasarnya bahasa yang harus mengenai sasarannya tidak selalu perlu beragam baik. PUEBI merupakan salah satu acuan dasar dari penggunaan bahasa Indonesia yang baik dan benar. Dalam PUEBI, telah diatur beberapa ketentuan mengenai pemakaian huruf, penulisan kata, pemakaian tanda baca, dan penulisan unsur serapan. Acuan penggunaan bahasa Indonesia yang benar tidak hanya berdasarkan PUEBI. Penggunaan bahasa Indonesia yang benar dapat mengacu pula pada Tata Bahasa Baku Bahasa Indonesia, Kamus Besar Bahasa Indonesia, dan Pedoman Umum Pembentukan Istilah.

2. Etika menghubungi Dosen

Dari Hasil penelitian menggunakan kuesioner berpandangan bahwa etika dalam berkomunikasi via whatsapp kepada 
dosen harus diperhatikan, tidak boleh bertele-tele dan tidak membingungkan, serta harus singkat, padat dan jelas. Adapun sistematikanya yaitu dengan cara mengucapkan salam terlebih dahulu, tidak lupa untuk memperkenalkan diri, kemudian langsung menyebutkan tujuan menghubungi Dosen tersebut dan jangan lupa juga untuk mengucapkan rasa terimakasih di akhir pesan.

Ketika hendak mengirimkan pesan teks harus diperhatikan juga jam efektifnya, tidak boleh menghubungi Dosen jika sudah larut malam karena bisa dianggap tidak sopan. Namun tidak sedikit mahasiswa yang mengirim pesan teks kepada Dosen di luar jam kerja. Pengiriman melalui aplikasi pesan teks di era ini tentu berbasis digital yang prosesnya hanya sepersekian detik untuk saling terhubung. Sehingga kapanpun dan dimanapun, dosen dapat menerima pesan teks dari mahasiswa yang isi dan bahanyanya pun beragam. Sebaiknya, mengirim pesan teks tersebut harus dilakukan pada jam kerja agar tidak menggangu waktu dari dosen tersebut.

Diera ini cara mahasiswa mengirim pesan teks kepada Dosen berdasarkan pengetahuan dan sikap dalam diri merupakan bagian dari etika dalam individu. Anggapan terhadap waktu, format, dan bahasa dalam pengiriman pesan teks yang muncul dari dalam diri merupakan bagian dari etika individu. Standar penulisan pesan teks yang dikirim oleh mahasiswa kepada Dosen kiranya memperhatikan waktu pengiriman, format pesan, dan bahasa. Format pesan merupakan bagian yang paling sering menjadi persoalan. Format yang sering digunakan oleh sebagian besar mahasiswa ketika menghubungi dosen menggunakan urutan sebagai berikut: Menulis salam, identitas yang jelas (nama lengkap, NIM, kelas), menyebutkan keperluan, berterima kasih, dan penutup.

Selain format, penggunaan Bahasa Indonesia yang baik dan benar serta gaya penulisan menjadi persoalan berikutnya. Menurut teori etika berbahasa Abdul chaer dan Leonie Agustina (2004) yaitu: suatu hal yang harus dikatakan pada waktu dan keadaan tertentu, ragam bahasa yang digunakan, kapan dan bagaimana menggunakan giliran berbicara dan menyela pembicaraan, kapan harus diam, serta kualitas suara dan sikap fisik. Penggunaan bahasa dan penulisan dalam pesan teks yang baik kepada dosen adalah bahasa yang formal dan tidak disingkat. Namun berdasarkan hasil penelitian, mahasiswa tidak selalu bersikap sebagaimana yang tertulis dalam penyataan terkait etika berbahasa tersebut.

Berdasarkan pengertian komunikasi dan etika pada bagian sebelumnya, dapat disimpulkan bahwa etika komunikasi merupakan aturan/tata cara serta norma yang mengatur seseorang dalam berkomunikasi. Agar tercapainya komunikasi efektif, seseorang perlu memahami asasasas dalam komunikasi manusia. Brent D. Ruben dan Lea P. Stewart (2013) membagi aspek komunikasi menjadi aspek komunikasi yang dapat kita lihat dan aspek komunikasi yang tidak bisa kita lihat. Aspek komunikasi yang dapat kita lihat, diantaranya orang, simbol dan teknologi. Sedangkan aspek komunikasi yang tidak bisa kita lihat, yaitu makna, pembelajaran, subjektivitas, negosiasi, budaya, konteks dan tingkat interaksi, referensi diri, refleksivitas diri, etika dan keniscayaan. Di antara beragam aspek tersebut, aspek etika merupakan aspek penting yang menjadi bagian setiap profesi.

\section{SIMPULAN DAN SARAN \\ A. Simpulan}

Meski secara umum pemakaian Bahasa Indonesia yang baik dan benar serta etika mahasiswa ketika berkomunikasi dengan Dosen masih baik, sebagian besar mahasiswa memilih menggunakan gaya bahasa campuran ketika berkomunikasi dengan Dosen melalui aplikasi whatsapp, yaitu campuran antara gaya bahasa formal dengan gaya bahasa santai. Hal ini perlu dipelajari dan dikoreksi sebagai sebuah pergeseran budaya komunikasi yang bisa jadi berdampak kurang positif. Aplikasi pesan teks seperti whatsapp dalam urusan akademik menjadi sebuah kebutuhan sendiri bagi mahasiswa. Etika komunikasi mahasiswa kepada dosen melalui aplikasi whatsapp di era sesudah kemunculan android banyak menyoroti pada pesan dan proses komunikasinya. Bagian yang sering kali menimbulkan persoalan adalah dari segi pesan terutama bahasa dan format pesan itu sendiri. Sikap awal, informasi, dan normanorma moral banyak memberikan pengaruh 
terhadap cara, bahasa, dan perubahan bagi mahasiswa menghubungi dosen melalui aplikasi whatsapp.

\section{B. Saran}

Adapun beberapa etika yang diperhatikan dalam berkomunikasi lewat whatsapp dengan dosen diantaranya; perhatikan waktu yang tepat untuk menghubungi dosen, awali pesan dengan ucapan salam atau sapaan, perkenalkan diri, pastikan pemilihan kata atau tanda baca yang baik, akhiri pesan dengan ucapan terima kasih dan salam.

\section{DAFTAR RUJUKAN}

Bahar, H, I Iswan, V H Sundi, N L Fitri, and ... 2020. "Pembelajaran Beyond Centers and Circle Time (Bcct) Berbasis Al-Qur'an Dalam Peningkatan Nilai-Nilai Karakter Bagi Anak Usia Dini." ... Jurnal Pendidikan Anak ... 4, no. 2:

145-55.

https://doi.org/https://doi.org/10.24853/ yby.4.2.145-155.

Basri, Hasan. 2021. "Integrasi Nilai-Nilai Tauhid Pada Pelajaran Sains Bagi Siswa Sekolah Dasar Islam Terpadu." Tadabbur: Jurnal Peradaban Islam 3, no. 1: 164-79. https://doi.org/10.22373/tadabbur.v3i1.15 $\underline{3}$.

Brent, D. Ruben dan Lea P. Stewart. (2013). Komunikasi dan Perilaku Manusia. Jakarta: PT RajaGrafindo Persada

Chaer, Abdul dan Leonie Agustina. 2004. Sosiolinguistik. Jakarta: Rineka Cipta.

Dhin, Cut Nya. 2020. "Kepedulian Orang Tua Terhadap Pendidikan Agama Siswa." Jurnal Kinerja Pendidikan 2, no. 3: 565-77.

Dikdik Febianto, Firli Nur Fadhillah, Ghani Wiharlan, Mugia Rizky Nugraha. 2019. Artikel: "Etika Mahasiswa Dalam Berkomunikasi Dengan Dosen Menggunakan Aplikasi Whatsapp". Jawa Barat: IKIP Siliwangi
Fahmi, Muhammad Nahdi, and Sofyan Susanto. 2018. "Implementasi Pembiasaan Pendidikan Islam Dalam Membentuk Karakter Religius Siswa Sekolah Dasar." Pedagogia: Jurnal Pendidikan 7, no. 2: 8589.

https://doi.org/10.21070/pedagogia.v7i2.1 592.

Fitri, Nur Lailatul. 2017. "Peran Orang Tua Dalam Membentuk Akhlak Anak Sejak Dini." AlHikmah: Indonesian Journal of Early Childhood Islamic Education 1, no. 2: 15568. https://doi.org/10.35896/ijecie.v1i2.11.

Putra, Ferdinan. 2018. Karya Tulis Ilmiah: "Etika Komunikasi Mahasiswa Kepada Dosen Melalui Aplikasi

Suherman, M. M. (2019). Penerapan Bimbingan Kelompok dengan Teknik Peer Group untuk Meningkatkan Kemampuan Komunikasi Siswa. QUANTA, 3(2), 29-35.

Tambak, Syahraini. 2019. "Pendidikan Etika Bergaul Islami Dalam Keluarga 'Nilai Pendidikan Etika Berlaku Adil Orangtua Dengan Anak Dalam Pergaulan Keluarga Perspektif Hadits.'” Jurnal Pendidikan Agama Islam Al-Thariqah 4, no. 1: 1-20. https://doi.org/10.25299/al-

thariqah.2019.vol4(1).2910.

Umroh, Ida Latifatul. 2019. "Peran Orang Umroh, I. L. (2019). Peran Orang Tua Dalam Mendidik Anak Sejak Dini Secaraa Islami Di Era Milenial 4.0. Ta'lim: Jurnal Studi Pendidikan Islam, 2(2), 208-225. Http://EJurnal.Unisda.Ac.Id/Index.Php/Talim/Articl e/View/1644Tua Dalam Mendidik Ana." Ta'lim : Jurnal Studi Pendidikan Islam 2, no. 2: 208-25. http://ejurnal.unisda.ac.id/index.php/talim/article/ view/1644. 